ORIGINAL ARTICLE

\title{
The patient's lament: hidden key to effective communication: how to recognise and transform
}

\section{B Bub}

J Med Ethics; Medical Humanities 2004;30:63-69

"Our dancing is changed into mourning" Lamentations 5:15 to "you turned my lament into dancing" Psalm 30:12.

Numerous studies and well publicised complaints from the public have long revealed a pressing need for physicians to improve their communication skills and their ability to interpret and respond appropriately to what they hear from patients. Rushed and dispirited, physicians are routinely urged to become more compassionate and to spend more time listening. This article challenges the myth that listening is a time consuming art propelled by compassion and demonstrates that it is in fact a highly active professional skill that can be greatly clarified and simplified for practising physicians. The lament is offered as a universally encountered, sometimes masked, expression that patients need to have heard and validated. An intellectual understanding of the lament as a symptom of suffering greatly facilitates the listening process and enables the listener to respond therapeutically. This saves time, improves quality of care, and enhances the wellbeing and satisfaction of both physician and patient.

Correspondence to: B Bub, 19 Arnold Drive, Woodstock NY, USA; docbarryb@aol.com

Accepted 2 June 2004

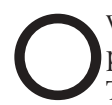
ver the years, patients have viewed physicians as both a blessing and a curse. The price of cure is often additional suffering imposed on patients by expensive, uncomfortable, and sometimes painful treatments. It is not surprising, therefore, that physicians are frequently the butt of patient laments:

When you are in need of a physician, you esteem him like a god; when he has brought you out of danger, consider him a kin; when you have been cured he becomes human like yourself; when he sends his bill you think of him as a devil.'

Or, as Chekhov famously put it: "Doctors are just the same as lawyers; the only difference is that lawyers merely rob you, whereas doctors rob and kill you too".

Physicians too have a long history of laments, mostly ones that centre on demands of patients or despair over harsh working conditions:
My duties to the Sultan are very heavy. I am obliged to visit him every day, early in the morning, and when he or any of his children or concubines are indisposed, I cannot leave Cairo but must stay during most of the day... When night falls, I am so exhausted I can hardly speak. ${ }^{2}$

The spectrum of disease has changed considerably over the centuries. Epidemics of diphtheria, plague, cholera, and smallpox no longer sweep across the Western world. Instead, visits to physicians are often related to the effects of stress and the management of chronic illness such as arthritis, diabetes, and hypertension. Treatment of these conditions is often complex, requiring behavioural modification, counselling, and development of a healing doctor/patient partnership. With physicians poorly trained to do this, and the medical system becoming increasingly impersonal, the modern day lament of patients is that physicians do not spend enough time with them, do not listen to them, and do not understand them.

Patients have reason to complain. In one study, only $17 \%$ of patients classified as clinically anxious and only $6 \%$ of those classified as clinically depressed were perceived as such by their oncologists. ${ }^{3}$ In another, physicians responded positively to patient clues about their emotional state in only $38 \%$ of surgical cases and $21 \%$ in primary care settings. ${ }^{4}$

Physicians in turn lament their many losses in the healthcare revolution, ${ }^{5}$ and the pressures of managed care, over-regulation, and the treadmill of practice that provide insufficient time to spend with patients. This incessant complaining has been described by Brouilette as the physician moaning syndrome. ${ }^{7}$ He states that this syndrome can be found in its most severe form wherever physicians congregate-for example in doctors' lounges. There, he writes: "They complain of chronic fatigue, depression, and loss of self esteem".

Dissatisfaction with physician communication can turn patients toward anger and litigation. ${ }^{8-11}$ Physicians, deprived of the positive feedback that comes from appreciative patients, often become demoralised, suffer burnout, and, not uncommonly, choose to retire prematurely. The title of a New York Times article of December 16, 2001 by Jennifer Steinhauer: "Anger at both ends of the stethoscope," graphically alludes to this mutual dissatisfaction with the status quo.

This mutual dissatisfaction poses a pressing challenge to the medical profession: how to improve the quality of doctor/patient communication so that patients feel adequately listened 
to and understood, without adding an additional time burden to physicians - that is, how to listen better rather than longer.

Additionally, in order to listen better, physicians need to know what to listen for; to understand the significance of what is being heard, and to know how to respond therapeutically. This is analogous to auscultation of the heart-knowing specifically what abnormal heart sounds and murmurs to listen for; what the differential diagnosis might be, and the appropriate follow up.

A high percentage of physicians report greatly inadequate training in psychotherapy and communication skills. ${ }^{12}{ }^{13}$ This, despite the fact that the major portion of mental health care is provided in the primary care setting ${ }^{14}$ and depression-for example-is frequently encountered in all practice settings, particularly in the elderly. ${ }^{15}$

Whereas only $5 \%$ of older patients who kill themselves have seen a mental health professional during the 3 months before death, $70 \%$ have seen their primary care physician in this time period, with up to $25 \%$ having seen their physician within one day. ${ }^{16}$

In a survey of oncologists, $74 \%$ of whom reported breaking bad news to patients in excess of five times a month, only $7.8 \%$ had any formal training in techniques of responding to patient emotions. ${ }^{17}$

These challenges can be responded to by altering the culture so that listening in medicine is not perceived as an act of benevolence born out of compassion but is instead approached as an essential clinical skill that is as much science as art. Having accomplished this, the next step is to clarify and simplify communication concepts and provide practical tools for diagnosis and treatment so that the average busy physician is empowered to listen and counsel efficiently and effectively. As this aspect of practice becomes more rewarding, the physician may be stimulated to study more complex communication and psychotherapy skills.

Simplifying communication begins with noticing that there is something universal and specific that patients want heard and understood. This "something" is the "lament"an expression of suffering so pervasive, that it may well be considered the hidden agenda in every patient until proven otherwise. Since laments are universal, the physician may well find that relationships with colleagues, employees, family, and friends improve as their laments in turn are appreciated and acknowledged. Most importantly, validating one's own personal lament is an ultimate act of self care.

\section{THE LAMENT}

People who suffer, complain, cry, mourn, wail-that is, they lament. Classically this can be found in the biblical books, Lamentations and Job, which are suffused with themes of loneliness, abandonment, absence of meaning, suffering, sin, and guilt.

I am disgusted with life; I will give reign to my complaint, speak in the bitterness of my soul. ${ }^{18}$

Bitterly she weeps at night, tears upon her cheek. With not one to console her... ${ }^{19}$

Ordinary people's laments are encoded in rhyme and folklore:

Love is a toil and life is a trouble

Riches will fade and beauty will flee

Pleasures they dwindle and prices they double

And nothing is as I would wish it to be. ${ }^{20}$

The lament may be written, drawn, spoken, sung, wailed, cried, mimed, danced, shrugged, laughed, or born in silence.
It may also be expressed as physical symptoms. At least 33\% of somatic symptoms are medically unexplained, and these symptoms are chronic or recurrent in $20 \%$ to $25 \%$ of patients. There is a strong coexistence of anxiety and depression in these patients. ${ }^{21}$ It is conceivable that many suffering from chronic multiple functional somatic symptoms are in fact lamenting.

If the response to suffering is the lament, then surely patients have much to lament about as they experience trauma and losses from their illnesses. The term patient is derived from the Latin word patiens meaning "to suffer". Ironically, the term "patient lament" is an oxymoron since by definition to be a patient is to be patient and not to lament or complain. Still, patients do lament and often the impersonal, expensive, and complex healthcare system adds additional layers of trauma and suffering rather than injecting elements of validation and healing.

There is an inherent and mostly unaware need to have one's lament heard and validated. This might occur occasionally, but mostly people find listening to another's chronic complaints a frustrating and challenging experience. At best, laments are usually shrugged off. The letter to one medical journal, Note to doctors: stop whining, is typical. ${ }^{22} \mathrm{~A}$ column in the New York Times went further. Not only did the physician author demonstrate a remarkable lack of empathy with a medical resident's lament of being in a "chronically nervous state," she went on to preach that he needed to study and acquire empathy for his patients. Her recipe: "stay awake every third night for three years, tired aching, nauseated, and terrified that despite the very best intentions in the world you are about to make a terrible mistake" ${ }^{23}$

Physicians, deprived of empathy themselves, tend to lack the capacity to empathise with patients. Symptomatic of this, the condition of multiple functional symptoms is labelled somewhat disrespectfully by some as: the "fat folder syndrome" or the "familiar face syndrome".

Why is the lament so invisible to physicians?

Unlike in the pastoral care literature, there is little reference to the lament in medical journals. This is not totally surprising, since chaplains and physicians have different agendas. Though both professions visit the same patients, physicians focus on cure and relief of physical symptoms whereas chaplains dwell on issues of spiritual suffering. Consequently, they hear different narratives. Since the lament is often subtle or disguised, manifesting just as a shrug, a sigh, or even a fixed smile, it may easily be missed by someone not trained to look for it. This point can be illustrated by listening to a colleague:

\section{The fellow}

Returning from presenting at a conference, I found myself sharing a cab to the railway station with a young medical fellow. As we pulled up to the station, she commented: "I hope the train is on time. Amtrak is often late." She sighed and repeated: "Yes, they're erratic". While we waited for the train, which incidentally arrived on time, she asked what I taught.

"Listening skills to physicians-for example, how to recognise a lament" I responded.

"What is a lament?" she asked.

"You just did it, a few minutes ago" I replied.

She looked at me quizzically.

"Remember your comment about Amtrak, that was a lament. You sighed as you said it, and you repeated yourself. You know when a word or a phrase is repeated in the Bible, it's always significant. Same in real life. 
Neither of us wants the train to be late, but for you it has a special significance."

We seated ourselves across the aisle from one another. She chatted easily about her job. How fortunate she was to have it. It required some travel, but was otherwise a "plum". There were many perks, such as her recent eight weeks maternity leave instead of the usual six.

"Yes," she told me, "my friends envy me having a job I actually enjoy, something unusual in this day and age." "How old is your baby?" I asked.

"She's eight months old, the joy of my life. My husband's babysitting. She will be asleep by the time I get home, I guess," she replied, her smile now less pronounced.

"Is it hard for you to be away from them?" I asked.

"It is," she said, her voice now dropped to barely a whisper. "It's been tough. Still, it's too good a job to give up." Her eyes were misty.

Leaning forward across the aisle toward her, in an invisible "bubble" of rapport, I responded that it had to be wrenching having to make the choice between work and baby. Regardless how great the job, her losses were big.

She nodded, silent now.

After a while: "What will you do with the next one?" I asked.

"No way will I return to work!" her voice now assertive and strong.

She then paused for a moment: "So, I was lamenting, ha? Go figure."

A short while later, when I disembarked at my stop, she flashed a broad goodbye smile. She was sitting straighter. A lightness had come over her.

\section{WHAT EXACTLY IS A LAMENT?}

Simply stated, a lament is an expression of suffering, a crying out of pain-physical, emotional, and spiritual. The Hebrew title for the book of Lamentations is Eikhah, meaning "How?!" The rough sound of this word embodies the harshness of the pain. The lament contains some elements of hopelessness, helplessness, disempowerment, absence of choice, pessimism, grief, weariness, lack of meaning, isolation-from others, from God, from self-perhaps anger, fear, shame, anguish, self blame, guilt, and cynicism.

Paradoxically, it also includes hope, since in lamenting, the individual is reaching out from a place of isolation, with the hope (often unaware) that the cry will be heard. The ultimate state of despair and loss of faith is found in a person who cannot lament. Hence, behind the incorrigible optimist may be someone who does not experience the luxury of being able to express mourning.

The lament is really more than an expression, rather it is part of the experience of new reality. "The delicate dance between expression and experience, continues interdependently, each leading, each following, each birthing the other." ${ }^{24}$ Sometimes the lament seems to take over the very identity of the individual with a telling and retelling of the trauma for years after the event. In this case, there is little that the listener can say or do that has any impact on the lamenter.

A lament may be acute or chronic, based on the nature of the trauma, the losses, and the suffering it produces.

\section{The acute lament}

The acute lament is a normal, healthy, integral part of the healing process. Traumas always result in losses. In the face of sudden severe losses, crying, bemoaning, and wailing serve to generate the energy that frees the individual from the numbness created by the shock of trauma and allows the traumatised individual to adjust and realign to the new reality.

With the lament, it is useful to think of energy being transformed into movement. In the acute lament, movement is vertical: "descent for the purpose of ascent" as Rebbe Nachman of Breslov described it in the 18th century. ${ }^{25}$ Sometimes the deep, dark despair is so severe that descending into it feels like death and then as hope begins to return, ascending into a world of new possibilities feels like rebirth. The poet David Whyte eloquently describes this experience as a descent into "the well of tears". ${ }^{26}$

In the usual course of events, trauma is followed by what we term The Healing Sequence. A simple metaphor that illustrates this healing sequence is one of a child falling and scraping a knee. The injury (trauma) results in pain (suffering), which leads to crying (lamenting); the parent hears and comforts the child (listening) and the child runs off and plays again (healing).

With a more serious trauma, the Healing Sequence follows a similar flow: a financial reversal, an accident, an illness, a death, etc (trauma) leads to losses-emotional, spiritual or physical (suffering) - which leads to crying, wailing, collapsing, moaning (lamenting). As these losses are validated by the self or another (listening) they become integrated (healing) and the individual moves on.

Alternatively, with overwhelming trauma the response may be stunned, numbed, silence, not necessarily lament. In this case, movement is frozen rather than directed. For some, this Acute Stress Reaction (ASR) may eventually lead to Post Traumatic Stress Disorder (PTSD). Acute Stress Reaction and PTSD can manifest when patients have been exposed to traumas such as accidents, acts of violence, sudden loss of a loved one, acute myocardial infarction, spontaneous abortion, and diagnosis of cancer. Physicians too may experience this when they discover their medical mistakes or when they are subjected to the stresses of litigation. ${ }^{27}$

\section{The chronic lament}

A lament may become chronic when grief following an acute trauma is interrupted, disowned, or disenfranchised and there is no opportunity for complete mourning. It may also occur when the onset of trauma is gradual or trauma is unrelenting.

The traumas leading to the chronic lament experienced in medical practice may be dramatic and obvious, mostly they are not. The mother of a sick child, the spouse of an Alzheimer's patient, the patient with an arthritic knee, the doctor fighting managed care, the under appreciated receptionist, the overworked nurse-all experience traumas and losses, and tend to lament them.

Being denied the transformative power that comes from openly expressing grief, energy, needing to go somewhere, seeps out. The poet Rumi described this in the 13th century: "I spill sad energy everywhere. My story gets told in various ways: a romance, a dirty joke, a war, a vacancy." 28

The movement of energy with the chronic lament is circular and non-linear. It does not lead to healing. Dr Simcha Raphael, psychotherapist, calls this "stuck movement". Like a tape recording played over and over, the lament leads nowhere.

The lamenter needing to be heard, repeats the lament constantly, often unconsciously and in a number of vague ways. It may also be almost totally masked - the patient with a fixed smile, the always joking physician, the cynic, the intellectual, the loner, the disruptive physician (or patient), the workaholic. Consequently, the lament is frequently missed. 
The chronic lament is mostly counterproductive, alienating rather than drawing others closer. Like a foreign body in a wound, it draws attention to itself and inhibits healing rather than facilitating it. Only when genuine emotion is felt and expressed can the lament begin to shift into constructive action. In other words, when the chronic lamenter experiences sadness or weeps in the course of talking, this is a positive sign.

Certain groups of individuals are at higher risk for laments-the recently separated or divorced, the unemployed, patients, particularly the elderly. The nursing home patient is typical.

In the following example, the physician is frustrated-he has tried everything and nothing ever seems to help his patient. Even antidepressants have not helped. He does not feel compassionate. If anything he is a little angry. Now he has decided to try a different approach. He will listen, avoid controlling the dialogue, encourage her emotions, and validate them. He will relinquish sole responsibility for "making it better".

\section{The nursing home patient}

$\mathrm{D}=$ doctor, $\mathrm{P}=$ patient

D: How are you today Mrs Cohn? (D inquiring about her as a person, not her knees.)

P: Not so good doctor. (She sighs.) (D thinks he hears a lament.)

D: Why, what's happening? (D now sits down for better eye contact, signals he intends to listen.)

P: It's my knees. The medicine you gave me isn't working. Just like the others. (D momentarily feels annoyed, and silently acknowledges his frustration then parks it.)

D: So you are having a lot of pain? (D acknowledges and invites further response.)

P: Yes, and it's affecting my bowels. Just can't go every day. (She pauses. D tolerates this.)

And every five minutes I have to pass my water. The water pills don't help matters.

D: Must be very difficult going to the bathroom with your knees being so painful. ( $D$ is validating her experience.)

P: You cannot imagine.

D: No, I can't. How do you cope? (D signals his empathy.)

P: I have to call the nurse to come help me. And you know what they are like. Always so busy.

D: And you used to be so independent. ( $D$ identifies and labels loss of independence.)

P: I was. I stood in the grocery store from six in the morning to nine at night. Never asked for help.

D: You have had so many losses in the last few years. ( $D$ making the point she's had more losses.)

P: Yes. I had to sell my home-such a beautiful house, I lived in it for forty years, raised all my children in it. They made me sell my car, my friends are dead. Better I should be gone.

D: You feel you are better off dead?

P: Yes (sobbing now), don't worry, I'm not going to do anything.

D: (after a pause) This must very painful for you, feeling so helpless. (D has identified another loss.)

P: It is. It feels terrible being alone and needing help. Nothing to look forward to. None of my old friends are alive and my family doesn't come by so often anymore. (Isolation, loneliness - other losses are identified.)

D: I'm sorry. With you feeling so bad, how can I be most helpful to you? (D making an empowering suggestion.)

P: I know you can't take all the pain away, perhaps something I can take once in a while if the pain is too severe. And something for my bowels. Thank you doctor.
D: (taking her hand) OK, I will be happy to do that and I'll see you again in 2 weeks. ( $D$ is saying, in effect, I am here for you.)

Over the next few months she begins to look forward to his visits. They talk about her former life. He shares a little about his. Compassion emerges. He now appreciates her many losses-independence, pride, empowerment, physical control, etc. He recognises her anger, shame, despair, isolation, and helplessness. He no longer dreads visiting her, so his own sense of wellbeing improves. He also finds he has to spend less time fielding calls from the nursing home.

There are a number of reasons why a chronic lament might occur.

\section{CHRONIC LAMENTS CAUSED BY DISENFRANCHISED GRIEF}

The supervisor

She is successful, well liked at work, and enjoys a sense of comradeship with her colleagues. Much to her delight, she is rewarded with a promotion. Later she notices that the atmosphere at work has subtly changed. She is no longer invited by her former coworkers to join them during coffee breaks. Recently she had to discipline one of them and that was very uncomfortable for her. She feels empty and tired and cannot understand why since she has lots to be thankful for. She thinks she will see her doctor for some blood tests.

Eventually she sees a therapist and learns that transitions, even good ones, are always accompanied by some losses. When these losses are not anticipated and mourned, they end up becoming burdens.

\section{The resident}

The head of the residency programme receives reports that one of his physicians demonstrates irritability, sarcasm, and a negative attitude toward nurses and patients. He invites the resident for a walk and talk. He asks about the young man's life and learns that the resident, a native of India, comes from a very closely knit family. A few months ago he missed his brother's wedding because he could not take time off to return home. He tells himself he should be used to this by now, after all the years of study in medical school. This is the price one pays for being a doctor, isn't it?

\section{The obstetrician}

She does not know why she keeps bursting into tears whenever the topic of her malpractice suit comes up. Her colleagues tell her she did nothing wrong, has nothing to fear, and that litigation is a normal part of medical practice. She should consider herself fortunate that this is only her first lawsuit. She now dreads seeing patients, and is contemplating quitting obstetrics.

\section{The family doctor}

"You think you have problems! Look at me, I work twelve hours a day, reimbursement is down, work isn't fun anymore. You don't hear me complain." (Telephone call with a friend December 2003.)

\section{CHRONIC LAMENT CAUSED BY INTERRUPTED GRIEF}

Sometimes losses are just too great and mourning is just too painful. Some prefer to avoid inconsolable grief and instead choose to live "lives of quiet desperation," (as Henry David Thoreau put it) neither experiencing the depths of despair nor the peaks of joy. Their laments may slip out from time to time. Others may find that circumstances prevent them being able to immerse in mourning.

\section{The widow}

There are funeral arrangements to organise, insurances, taxes, finances to sort out. Decisions such as where to live 
need to be made. It is all so rushed, since his death was so unexpected. Weeks fly by, now grief hits in waves. When asked how she is, she smiles and responds she is fine. Nights are the hardest, so she visits her doctor regularly to renew her prescription for sleeping pills.

\section{CHRONIC LAMENT CAUSED BY ONGOING TRAUMA The family physician}

A typical successful doctor, he works 60 hours plus a week. Two years ago his wife, who was also his office manager, divorced him. The front office has been a shambles since the new manager does not seem to be coping. Their two teenage daughters chose to live with him. This has been a mixed blessing since they are both acting out, with one failing at school and the other displaying poor judgment in her choice of boyfriends. A few months ago his eldest daughter crashed her car. He feels he is constantly "putting out fires". Much of the time he is tired and cranky. One of his few pleasures is being treated to lunch by those pretty pharmaceutical reps. They listen attentively to him as he shares his frustrations. He also often unburdens when he encounters his colleagues in the hospital, though they seem to be avoiding him these days.

\section{HOW TO IDENTIFY A CHRONIC LAMENT Anticipate it}

Common things occur commonly therefore expect to hear suffering from patients (and healthcare professionals.)

\section{Listen for clues}

All senses are utilised in active listening. Notice handshake, eye contact, facial expression, body posture, speech pattern, and choice of language. The theme of the lamenting person's narrative is often peppered with disempowering words such as buts, can'ts, shoulds, musts, and if onlys. Notice also: hopelessness, pessimism, weariness, loneliness, and negativity.

\section{Notice one's own response}

One of many listening myths is that physicians need to learn to identify and control their emotions in the interest of objectivity..$^{29}$ Far better that physicians befriend, understand, support, and integrate their emotions so that they can be used in listening. Asking oneself:

Am I finding myself wanting to avoid this person? Do I find myself yawning, bored, and irritated by our conversation?

Do I feel redundant here, as if this person doesn't see me? Am I hearing a tape and it doesn't matter if I am in the room or not?

Were we talking and then the conversation was hijacked by a lament?

Do I feel stimulated to offer advice, counsel, or fix a problem?

Do I notice an emotional mismatch? Is the story powerful but the delivery flat and emotionless?

Any of the above suggests one is hearing a lament.

\section{HOW TO RESPOND APPROPRIATELY TO A LAMENT}

This is not easy, particularly for physicians who are trained to actively seek pathology in others and eradicate it, rather than to find health and support it-something far more helpful. Appropriate action is often therefore frequently counterintuitive. Creating space for someone to lament into-for example, may seem passive since it involves silence. Offering a silent presence is in fact a conscious act for a physician conditioned to be "productive" and busy. This is explained further below.

\section{The acute lament}

"When my last doctor gave me the news, I burst into tears. He then ran out of the room to fetch a nurse. You know doctors can't stand suffering!" A former patient

and

"I was devastated by the news. All I could think of was to ask how long I had to live. About two to four years, the doctor responded perfunctorily as if I had just asked him the time. He shuffled some papers and quickly disappeared." A cancer patient

The role of the physician is to accept that the acute lament is a healthy grieving that should not be aborted. This is one reason why following trauma, the use of tranquillisers and sedatives needs to be limited. A quiet supportive presence is helpful, meaningful, and healing. As mentioned before, silence may be an appropriate and active response since space is being created for grief. Here the listener serves as an invaluable witness to the experience. There are different types of silences-icy, cold, warm, intimate, etc. A helpful image of silence here is one in which "You hold in your heart the person with whom you are sitting, creating a warm silence where he or she knows you are not off somewhere else in your thoughts" (Rabbi Goldie Milgram, personal communication, 2003). Attention to "simple" details, such as having tissues on hand and informing the receptionist to hold calls, is important. Often long after the event, the sensitive role played by the physician will be recalled with appreciation.

\section{The chronic lament}

The hairdresser

Upon inquiry as to how he responded to his clients who seemed disheartened, pessimistic, disempowered, a hairdresser offered this insight:

\section{"I do not attempt to fix their problems. I listen, sympathise, and focus on improving the client's self image. I remember one young woman who shared her troubles with me. Finally, when I had finished she was thrilled by her appearance in the mirror. Walking to the door now with a bounce to her step, she paused, turned around and blurted: "You gone changed my way of walking!"}

Once the light bulb goes off as in "Aha! A lament!" then the listener needs to switch to "hairdresser mode" and pay particular attention to:

- being fully present and demonstrating this with eye contact, body language, and verbal response

- regardless of the temptation, not responding with advice, critique, or reassurance

- suspending personal judgment. Each person's suffering is unique. What seems trivial to one individual, may be very important to another

- offering therapeutic validation (the intentional use of validation in ways that enhance the recipient's capacity to face life's existential moments). ${ }^{30}$ It requires identifying the underlying emotions and reflecting back in a way that demonstrates understanding of them

- demonstrating empathy with phrases such as "I am sorry to hear this" or "What a sad time for you" 
- being very careful not to respond with: "I understand" or "I know what you are going through" because it is impossible to fully understand the suffering of another

- suspending attachment to outcomes

- silently acknowledging one's own anxiety at not being totally in control of the length, direction, or outcome of the encounter and reminding oneself that time listening often feels longer than reality.

When an individual feels heard and validated, laments tend to fade and the focus of the lamenter's attention may shift from lament to the listener. The listener may notice feeling visible for the first time in this encounter. Even though the listener has not fixed anything, a shift has occurred. This may be enough for most transient situations.

If there is an ongoing relationship, then opportunity for further healing exists. Facilitating a shift in the chronic lament requires a deeper understanding of the nature of suffering. The word suffer is derived from the Latin sufferre-to carry. To suffer is to carry, to endure. What is being carried is always an undesired burden. This knowledge provides the listener with therapeutic opportunities.

\section{Name the suffering}

Responding: "How do you possibly manage to cope?" or "You have endured so much, what keeps you going?" or words to that effect, raises the lamenter's awareness that he or she is suffering. This awareness alone serves to ease suffering. The renowned philosopher and Holocaust survivor Viktor Frankl articulated it well: "Emotion, which is suffering, ceases to be suffering when we form a clear and precise picture of it $^{\prime \prime}{ }^{31}$

\section{Identify losses}

Asking oneself: "What is this person being forced to carry or endure?" helps identify losses. Reflected back, this helps the lamenter connect to specific losses and to move into a phase of conscious mourning-a precondition for moving forward.

\section{Relieve isolation}

Not only is a burden being carried, it feels as if it is being carried alone. The very nature of suffering is separation and isolation. This can be understood from the perspective of a cancer patient. The moment the diagnosis is revealed this person now leaves the community of the healthy and faces an unknown future. As in the three stage "rite of passage" process described by Arnold van Gennep, this person having separated from society (stage 1 ) is now on a journey as an ill person (stage 2) and upon recovery returns to society (stage 3) somehow transformed by this life threatening experience. ${ }^{32}$ This entire process of detachment, journey, and return is an isolating and frightening one. Having the lament heard and supported, means that this burden is no longer being supported alone.

\section{Shift perception}

The lament tape may be played so often that it is experienced as the reality of the situation. This becomes a fixed image. When the listener reflects back what is heard-for example, "So you feel you have only one choice" this may stimulate awareness that this is a feeling and not necessarily reality. Images may shift. The question: "What do you think you need right now?" may sharpen the focus from lament to specific need. Reflecting the lament back in the form of a metaphor-for example, "You feel you are wandering in the wilderness," may also help reshape the image of the situation.

\section{Empower}

Powerlessness, helplessness is the lamenter's present reality. It is rarely absolute. Asking: "What supports or strengths do you have?" may help the lamenter connect with forgotten strengths. Asking "How may I be most helpful to you?" is also empowering because it hands over control to the lamenter. This question presents an opportunity for partnership and collaboration.

\section{Support faith}

For some, the lament is a cry to a higher power: Hear my suffering! Get me out of here, this is such a painful place! Clergy and chaplains are seen as messengers of God. Any human can fulfil this role, just by careful listening. Deep listening is in fact the spiritual experience some patients seem to need from their physicians. What is heard, the lament, can be reflected back in the form of a blessing, prayer, or affirmation. Listening becomes a powerful and moving experience.

Many will find comfort in reading Psalms, Job and Lamentations because they give voice to feelings of the sufferer.

\section{Support the best self}

Self perception is by definition subjective. The lamenter connects with helplessness, loss, failure, and shame. Positive qualities are often forgotten and self esteem suffers. Just as the hairdresser holding a mirror reflects a beautiful image, the listener can often quite sincerely remind the lamenter of personal strengths that are being overlooked.

\section{Introduce hope}

Without negating the negative perceptions of the lamenter, the listener through his/her spirit, positivity, humour, and humanity may stimulate some of these qualities in the person lamenting. Music, poetry, story all can lift the spirit, shift mood, optimism, and perception of the situation.

\section{Touch}

Nowadays regarded with suspicion, appropriate touch done with great care and consciousness can be very healing. A simple touching of the hand can mean a great deal to someone who feels isolated and estranged. Very careful listening has the same effect. Dan Bloom, gestalt psychotherapist, states this succinctly: "I touch by my listening".

\section{Attend to the gestalt of the medical encounter}

For the patient, there is life affirming power in the routine of the office visit. A visit to the doctor is an experience that extends far beyond the encounter alone. One physician, upon telling his patient with debilitating arthritis that he was retiring from practice, was taken aback when the 70 year old man burst into tears. "Doctor, I know you will refer me to someone else for care, but will he have large photos on the wall, little mementos from his trips on his desk, will he share sweet stories about his family with me?"

Utilise ritual

When losses have been openly lamented and grief has been expressed, then the time has come to move on to effective action. Recommending or assisting in creation of a ritual can help to support and facilitate this transition.

\section{Differential diagnosis}

Should the lament not resolve, or should it be associated with other features of major depression, then referral to a psychiatrist or treatment with antidepressants may be indicated.

Laments frequently coexist with or are triggered by organic illness. Diagnosing suffering does not relieve the physician from the responsibility of practising good clinical medicine and ensuring that patients receive appropriate investigations and treatment. 


\section{CONCLUSION}

Superbly trained to deal with physical illness, surveys reveal that most physicians have woefully inadequate training in communication and psychotherapy skills even though they are regularly expected to cope with issues of suffering, stress, trauma, and mental illness. The consequences include patient dissatisfaction, diminished quality of care, reduced physician morale and satisfaction, and increased incidence of litigation. If anything, these consequences add to the problem of poor communication rather than diminish it. In the interests of improving physicians' ability to understand and communicate, this article has focused attention on the lament, a pervasive condition that draws attention to underlying suffering. Benefits that accrue from hearing and responding to the lament include the bringing of spirituality and humanity into medical practice and the facilitation of partnership relationships between doctors and patients. The ensuing reduction of litigation, unnecessary investigation, and treatment, may save time and expense in the long term.

\section{ACKNOWLEDGEMENTS}

I wish to thank Rabbi B Taylor of the Healthcare Chaplaincy, New York City, for stimulating my interest in this topic.

\section{REFERENCES}

1 Preuss J. Julius Preuss' biblical and talmudic medicine. New York: Hebrew Pub Company, 1983.

2 Rosner F. The medical legacy of Moses Maimonides. Jersey City, NJ: KTAV Publishing House, 1998:4.

3 Newell S, Sanson-Fisher RW, Bonaventura A. How well do medical oncologists' perceptions reflect their patients' reported physical and psychosocial problems? Data from a survey of five oncologists. Cancer 1998;83:1640-51.

4 Levinson W, Gorawara-Bhat R, Lamb J. A study of patient clues and physician responses in primary care and surgical settings. JAMA 2000;284:1021-7.

5 Daugird A, Spencer D. Physician reactions to the health care revolution: a grief model approach. Arch Fam Med 1996;5:497-500.

6 Loder D. The saddest day of my life. Berks County Medical Record 1998;89:6.

7 Brouillette J. Physician moaning syndrome. J Florida M A 1996;83:139.

8 Moore PJ, Adler NE, Robertson PA. Medical malpractice: the effect of doctor/ patient relations on medical patient perceptions and malpractice intentions. West J Med 2000;173:244-50.
9 Vincent C, Young M, Phillips A. Why do people sue doctors? A study of patients and relatives taking legal action. Lancet 1994;343:1609-13.

10 Virshup B, Oppenberg A, Coleman M. Strategic risk management: reducing malpractice claims through more effective patient/doctor communication. Am J Med Qual 1999;14:153-9.

11 Beckman H, Markakis K, Suchman A, et al. The doctor/patient relationship and malpractice. Lessons from plaintiff depositions. Arch Intern Med 1994;154:1365-70.

12 Swanson J. Family physicians' approach to psychotherapy and counseling. Perceptions and practices. Can Fam Physician 1994;40:53-8.

13 Ashbury F, Iverson D, Krali B. Physician communication skills: results of a survey of general/family practitioners in Newfoundland. Newfoundland Med Educ Online $2001 ; 6: 1$. http://www.med-ed-online.org/res00014.htm (accessed 5 Sept 2004).

14 De Gruy F. Mental health care in the primary care setting: a paradigm problem. Families Systems \& Health 1997;15:3-23.

15 Meldon S, Emerman C, Shubert D, et al. Depression in geriatric ED patients: prevalence and recognition. Ann Emerg Med 1997;30:141-5.

16 Glaser V. Topics in geriatrics: Effective approaches to depression in older patients. Patient Care 2000;17:65-80.

17 Baile W, Buckman R, Lenzi R, et al. SPIKES - a six step protocol for delivering bad news: application to the patient with cancer. Oncologist 2000;5:302-11.

18 Holy Bible. Job x, 1

19 Holy Bible. Lamentations I, 2

20 Seeger P. Housewife's lament. Penelope isn't waiting any more. Rounder 4011: LP 1977.

21 Kroenke K. Patients presenting with somatic complaints: epidemiology, psychiatric comorbidity and management. Int J Methods Psychiatr Res 2003; 12:34-43.

22 Basskim L. Note to doctors: stop whining [letter]. Med Econ 1997; Nov 24: 20.

23 Zuger A. The hours that make a student an MD. New York Times 1999 Nov 21:16.

24 Byrne P. "Give sorrow words": lament-contemporary need for Job's old time religion. J Pastoral Care 2002;56:255-64.

25 Rebbe Nachman of Breslov. Likutey moharan 1 [vol 1] [trans Mykoff M, Bergman S]. Jerusalem: Breslov Research Institute, 1995: lesson 6, s 4.

26 Whyte D. Where many rivers meet. Langley, WA: Many Rivers Press, 1998.

27 Kennedy J. Physicians' feelings about themselves and their patients [letter]. JAMA 2002;287:1113.

28 Barks C. The essential Rumi. New York: Harper Collins, 1995.

29 Meier D, Back A, Morrison R. The inner life of the physician and care of the seriously ill. JAMA 2001;286:3007-14.

30 Schneider JM. Finding my way. Healing and transformation through loss and grief. Colfax, WI: Seasons Press, 1994.

31 Frankl VE. Man's search for meaning. Boston, MA: Beacon Press, 1946.

32 Gennep V. The rites of passage [trans Vizesom MB, Caffee GL]. London: Routledge and Kegan Paul, 1960. 